\title{
Transcriptome analysis of the fungal pathogen Rosellinia necatrix during infection of a susceptible avocado
} rootstock identifies potential mechanisms of pathogenesis

\author{
A. Zumaquero', S. Kanematsu ${ }^{2,3}$, H. Nakayashiki ${ }^{2}$, A. Matas ${ }^{4}$, E. Martínez-Ferri ${ }^{5}$, A. Barceló-Muñóz' ${ }^{1}$, F. Pliego-Alfaro ${ }^{4}$, \\ C. López-Herrera ${ }^{6}$, F. M. Cazorla ${ }^{7}$ and C. Pliego ${ }^{1 *}$
}

\begin{abstract}
Background: White root rot disease caused by Rosellinia necatrix is one of the most important threats affecting avocado productivity in tropical and subtropical climates. Control of this disease is complex and nowadays, lies in the use of physical and chemical methods, although none have proven to be fully effective. Detailed understanding of the molecular mechanisms underlying white root rot disease has the potential of aiding future developments in disease resistance and management. In this regard, this study used RNA-Seq technology to compare the transcriptomic profiles of $R$. necatrix during infection of susceptible avocado 'Dusa' roots with that obtained from the fungus cultured in rich medium.

Results: The transcriptomes from three biological replicates of $R$. necatrix colonizing avocado roots (RGA) and $R$. necatrix growing on potato dextrose agar media (RGPDA) were analyzed using Illumina sequencing. A total of 12 , 104 transcripts were obtained, among which 1937 were differentially expressed genes (DEG), 137 exclusively expressed in RGA and 160 in RGPDA. During the root infection process, genes involved in the production of fungal toxins, detoxification and transport of toxic compounds, hormone biosynthesis, gene silencing and plant cell wall degradation were overexpressed. Interestingly, 24 out of the 137 contigs expressed only during $R$. necatrix growth on avocado roots, were predicted as candidate effector proteins (CEP) with a probability above $60 \%$. The PHI (Pathogen Host Interaction) database revealed that three of the $R$. necatrix CEP showed homology with previously annotated effectors, already proven experimentally via pathogen-host interaction.

Conclusions: The analysis of the full-length transcriptome of $R$. necatrix during the infection process is suggesting that the success of this fungus to infect roots of diverse crops might be attributed to the production of different compounds which, singly or in combination, interfere with defense or signaling mechanisms shared among distinct plant families. The transcriptome analysis of $R$. necatrix during the infection process provides useful information and facilitates further research to a more in -depth understanding of the biology and virulence of this emergent pathogen. In turn, this will make possible to evolve novel strategies for white root rot management in avocado.
\end{abstract}

Keywords: Ascomycete, Effectors, Persea americana, Virulence, White root rot

\footnotetext{
* Correspondence: mclara.pliego@juntadeandalucia.es

'Department of Genomics and Biotechnology, IFAPA, Fruticultura Subtropical

y Mediterránea, Unidad Asociada de I + D + i al CSIC, Cortijo de la Cruz s/n,

29140 Málaga, Spain

Full list of author information is available at the end of the article
}

(c) The Author(s). 2019 Open Access This article is distributed under the terms of the Creative Commons Attribution 4.0 International License (http://creativecommons.org/licenses/by/4.0/), which permits unrestricted use, distribution, and

reproduction in any medium, provided you give appropriate credit to the original author(s) and the source, provide a link to the Creative Commons license, and indicate if changes were made. The Creative Commons Public Domain Dedication waiver (http://creativecommons.org/publicdomain/zero/1.0/) applies to the data made available in this article, unless otherwise stated. 


\section{Background}

Rosellinia necatrix is a soilborne ascomycete, belonging to the order Xylariales, which causes white root rot (WRR) disease in a wide range of commercially important crops and ornamental plants. It has been reported that $R$. necatrix can infect over 170 plant species from 63 genera and 30 families [1], listed in $344 R$. necatrixhost combinations by the United States Department of Agriculture [2]. This pathogen has a worldwide distribution being able to survive in temperate, tropical and subtropical climates [3-6].

In the Mediterranean region of Spain, WRR is especially damaging due to the co-occurrence of favorable environmental conditions for the development of the fungus and susceptible hosts such as avocado (Persea americana Mill.) and mango (Mangifera indica L.) [7, 8]. Nowadays it is considered as one of the most important threats affecting avocado productivity [7].

Affected avocado trees show rotten roots and are characterized by a yellowing of the leaves that eventually wilt and ultimately, results in death of the tree. $R$. necatrix root invasion usually occurs by the formation of mycelial aggregates over the root surface which penetrate the root tissues among epidermal and cortical cells and finally, collapse the vascular system of the plant [9]. Neither chemical nor physical methods have proven to be fully effective to control this disease due to the capacity of the fungus to survive in acidic soils as well as to colonize numerous hosts; in addition, the pathogen is quite resistant to drought [4, 7]. Nowadays, the obtainment of tolerant rootstocks appears as the most promising approach to control this disease and efforts are underway to reach this goal [10].To add future developments in disease resistance, systematic analysis of pathogenic fungi's genomes and transcriptomes has become a top priority. Thus, in recent years, many researchers have addressed transcriptomics studies of plant pathogenic fungi/host interactions [11-13]. The analyses of gene expression profiles associated with the fungal infection provides key sources for understanding fungal biology, leading to the identification of potential pathogenicity determinants [11, 14-17]. Recently, Shimizu et al. [13] provided a 44-Mb draft genome sequence of $R$. necatrix virulent strain W97, in which 12, 444 protein encoding genes were predicted. The transcriptome analysis of the hypovirulent strain W97, infected with the megabirnavirus 1 (RNmbv1), revealed that primary and secondary metabolism, as well as genes encoding transcriptional regulators, plant cell walldegradating enzymes (CWDE), and toxin production such as cytochalasin E, were greatly disturbed in the hypovirulent strain. In another study, the transcriptome analysis of the virulent $R$. necatrix strain (KACC40445) identified 10,616 full-length transcripts among which, pathogen related effectors and CWDE encoding genes were predicted [12]. Data presented in both transcriptomics studies are a valuable resource of genetic information; however, to get a deep insight into pathogenesis of $R$. necatrix a comprehensive transcriptomic analysis of a virulent $R$. necatrix strain interacting with its host is necessary. With this aim, this research addresses the comparison of the transcriptomic profiles of $R$. necatrix during infection of susceptible avocado 'Dusa' roots (RGA) and in vitro growth on PDA (Potato Dextrose Agar) media (RGPDA) using RNA-Seq technology. Functional classification based on assignments to publicly available datasets was conducted, and potential pathogenicity genes related to $R$. necatrix virulence were identified providing a better understanding of the WRR disease.

\section{Results}

Comparative transcriptome analysis of $R$. necatrix growing on avocado roots vs PDA medium

A transcriptome analysis was carried out to capture genes expressed during $R$. necatrix growth on susceptible 'Dusa' avocado roots and on PDA medium, in order to compare their expression profiles (Fig. 1). The RNA-Seq data including the raw reads from three biological replicates of $R$. necatrix $\mathrm{CH} 53$ virulent strain colonizing avocado roots (RGA1; RGA2 and RGA3) and growing on culture medium (RGPDA1; RGPDA2 and RGPDA3) were processed. A total of 12,104 transcripts were obtained, among which 11,807 were present in both conditions, while 137 and 160 transcripts were exclusively expressed in either RGA or RGPDA, respectively (Fig. 2). Total transcripts were subjected to statistical analysis to evaluate differential gene expression between RGA vs RGPDA test situations. Analyses resulted in 1937 differentially expressed genes (DEG), $61.9 \%$ induced and $38.1 \%$ repressed $(-2>$ fold change $(\mathrm{FC})>2$; P-value <0.05) (Fig. 3). A heat map of DEGs showed consistence in expression patterns among RGA1, RGA2 and RGA3 and among RGPDA1, RGPDA2 and RGPDA3, supporting the reliability of the RNA-Seq data (Fig. 4).

\section{Validation of the RNA-Seq analysis}

Differences found in gene expression profiles between RGA vs RGPDA were further verified through a quantitative real time PCR (qRT-PCR) assay on total cDNA samples from mycelia of three biological replicates. For this, five randomly selected genes over-expressed in RGA vs RGPDA and with different FC, were analyzed. Actin gene was used as reference gene for data normalization. The expression levels of these genes amplified by qRT-PCR are shown in Table 1. Although higher expression values were obtained by qRT-PCR 


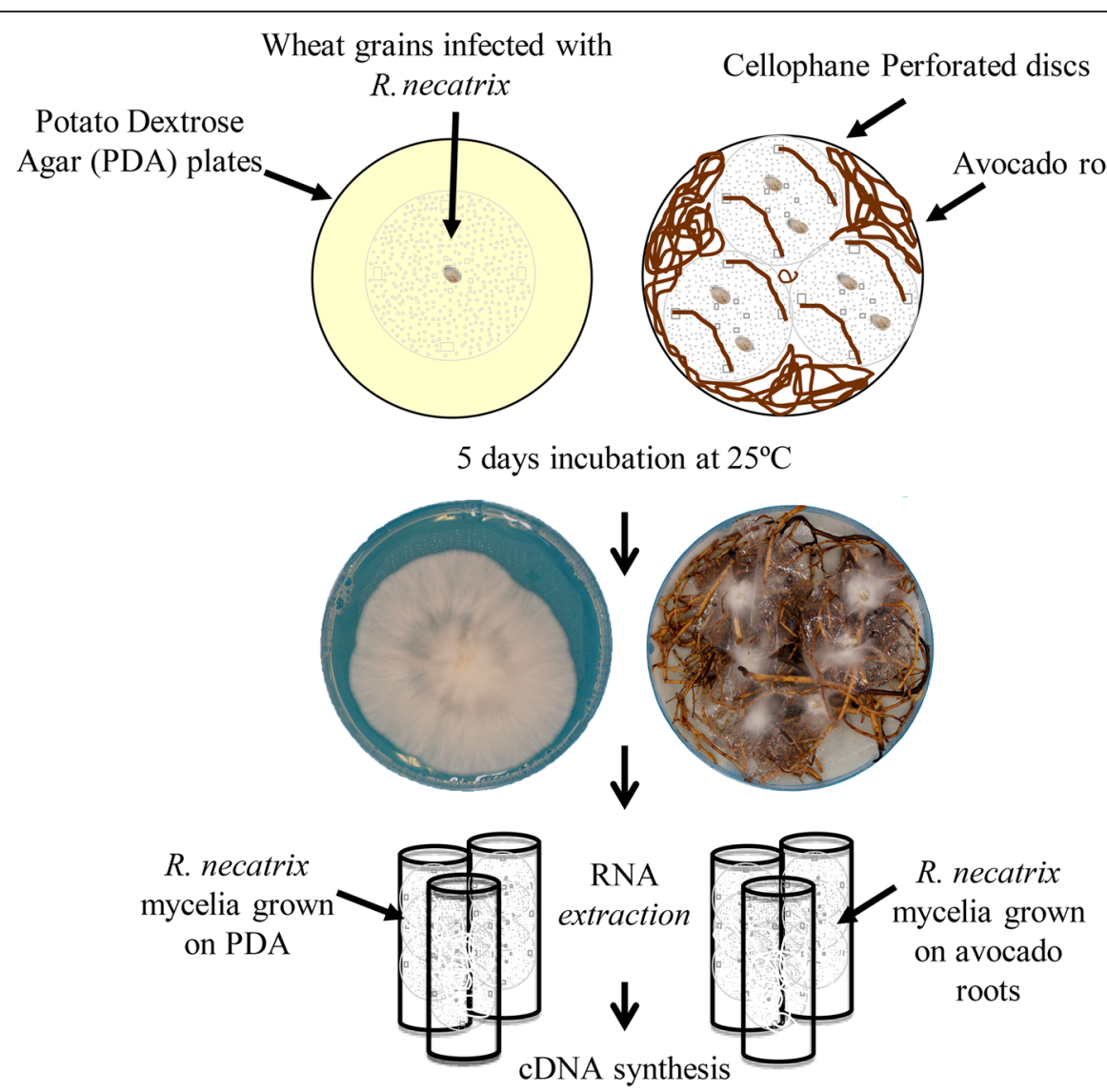

Fig. 1 RNA-Seq Experimental Design. Schematic representation of the transcriptome analysis carried out in $R$. necatrix growing on avocado roots in comparison with its growth on Potato Dextrose Agar (PDA) media

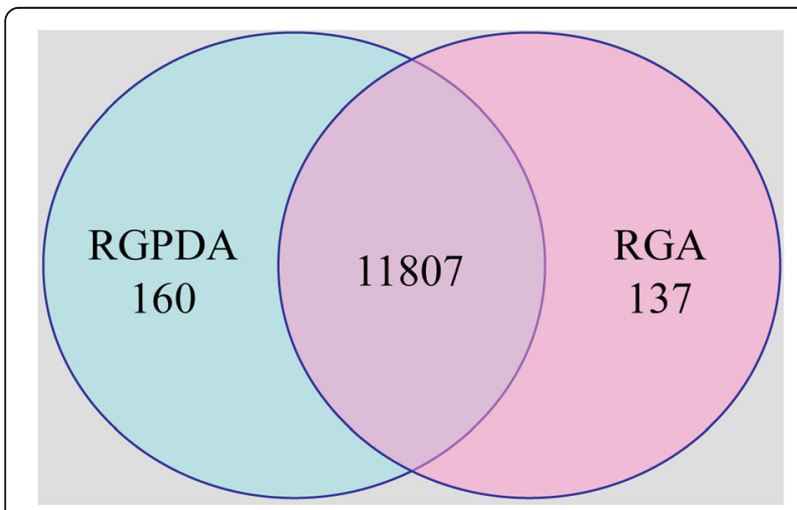

Fig. 2 Venn diagram of transcripts expressed during $R$. necatrix growth on avocado roots vs rich medium. Numbers of common and specific transcripts obtained in the transcriptome analysis of $R$. necatrix growing on avocado roots (RGA) in comparison with its growth on Potato Dextrose Agar media (RGPDA). Unique transcripts are shown in only one of the two circles while shared transcripts are illustrated where the circles meet than those observed on the RNA-Seq, results corroborated the overall differences found between the two samples (RGA and RGPDA) in the RNA-Seq analysis.

\section{Functional annotation and pathways analysis of} differentially expressed genes (DEGs)

To better understand the infection process of $R$. necatrix colonizing susceptible avocado roots, all differentially expressed genes were functionally enriched and categorized based on blast sequence homologies and gene ontology (GO) annotations using Blast2GO software [18] $(P<0.05)$, selecting the NCBI blast Fungi as taxonomy filter and default parameters. DEGs were significantly grouped into the regulation of eight molecular function (MF), such as heme binding (GO:0020037), iron ion binding (GO:0005506), oxidoreductase activity acting on $\mathrm{CH}-\mathrm{OH}$ group of donors (GO:0016614), flavin adenine dinucleotide binding (GO:0050660), cellulose binding (GO:0030248), NADP binding (GO:0050661), peroxidase activity (GO:0004601) and N,N-dimethylaniline monooxygenase activity (GO:0004499), and three biological process (BP), such as carbohydrate transport (GO:0008643), cellular oxidant detoxification (GO: 


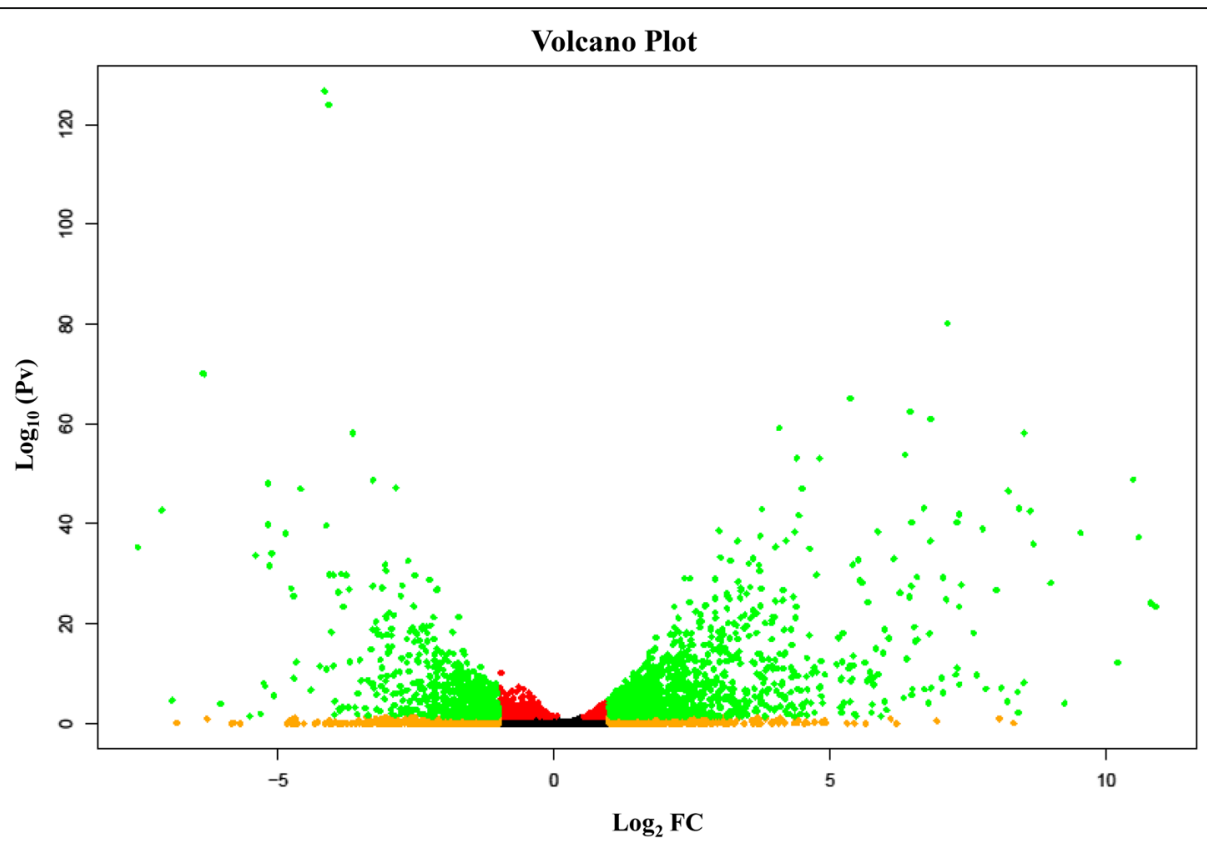

Fig. 3 Volcano Plot analysis of differentially expressed genes. Volcano plot summarizing the RNA-Seq DEGs. Significantly up-regulated (right side) or down-regulated (left side) DEGs in $R$. necatrix that also passed the 2 fold-change threshold is shown in green, or in red if the threshold criteria were not met. Non-significantly expressed genes are shown in orange if above or below the fold-change threshold, or black if no criteria were passed

0098869) and mycotoxin biosynthesis (GO:0043386) (Fig. 5a). To identify processes and functions overrepresented in $R$. necatrix during infection, GO term enrichment analysis was also applied to the Top 100 overexpressed genes (Fig. 5b). The functions of these DEGs were significantly enriched in the regulation of five $\mathrm{BP}$, such as oxido-reduction process (GO:0055114), cellulose catabolic process (GO:0030245), mycotoxin biosynthesis (GO:0043386), glucose import (GO:0046323) and response to hydrogen peroxide (GO:0042542), and $13 \mathrm{MF}$ (Fig. 5b) among which activities related to plant cell wall degradation, including glucosidase activity (GO: 0015926); endo-1,4- $\beta$-xylanase activity (G0:0031176); cellulose 1,4-beta-cellobiosidase activity (GO:0016162); xyloglucan-specific exo- $\beta-1,4$-glucanase activity (GO: 0033950) and arabinogalactan endo-1,4- $\beta$-galactosidase activity (GO:0031218) were found.To investigate the metabolic pathways affected in $R$. necatrix during avocado root infection, a KEGG pathway analysis was performed with Blast2go [18]. For the total of 1937 DEGs, 100 metabolic pathways that involved 208 genes were identified $(P$-value $<0.05)$. The metabolic pathways were reorganized into eleven categories (Table 2) being the nucleotides metabolism the one with the highest number of genes $(n=64)$. Interestingly, metabolic pathways involved in antibiotic and drug metabolism were also affected, in accordance with GO enrichment analysis results, where mycotoxin biosynthetic process was one of the molecular functions over-represented.

\section{Candidate genes involved in the pathogenesis of $R$. necatrix}

At least 69 transcripts showing homology to genes previously reported to be involved in fungal infection were identified among the 1937 DEGs. These include homologs to genes involved in the production of CWDE (Table 3), proteases, fungal toxins, detoxification and transport of toxic compounds, gibberellin biosynthesis and gene silencing (Table 4) as well as gene effectors (Table 5). Out of the 69 selected genes, 30 were associated with cell wall hydrolysis, among which 16 showed fold change (FC) values above 50, with three of them (SAMD00023353_0503130, SAMD00023353_6500680 and SAMD00023353 4001240) allocated in the top20 over-expressed genes in $R$. necatrix during avocado root-colonization (Table 3 and Additional file 1). Five genes were identified as proteases, two aspartic proteases and three serine proteases, with the contig SAMD00023353 1500930 expressed over 411 times in RGA vs RGPDA (Table 4). Five contigs showed homology to genes encoding fungal toxins, among which the contig SAMD00023353_5500610 encoding the putative aflatoxin $\mathrm{B} 1$ aldehyde reductase member 2 showed the higher transcript abundance with a FC value of 18.65 (Table 4).

Nineteen genes were related to degradation of toxic compounds such as reactive oxygen species (SAMD00023353_5200870), aflatoxins (SAMD00023353_ 


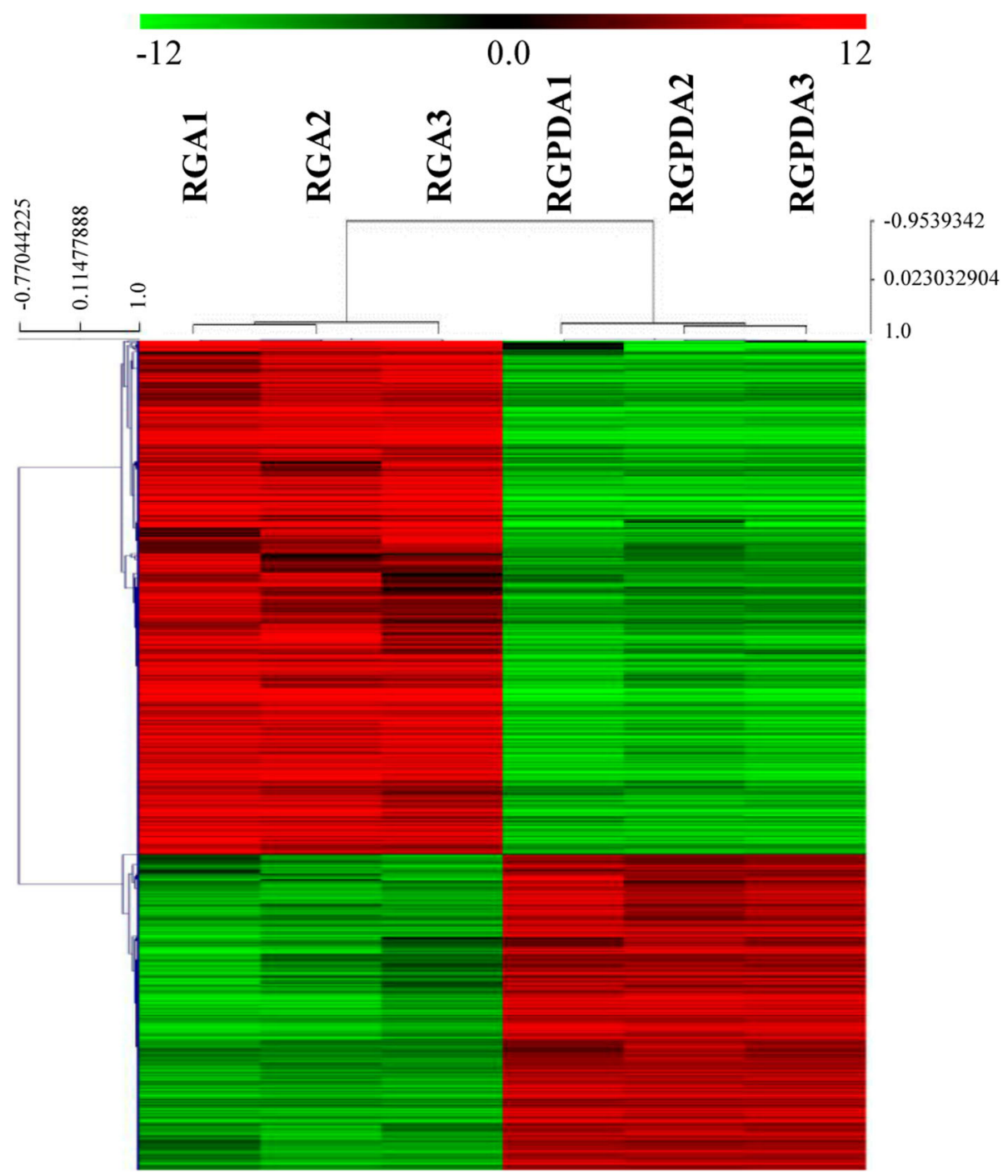

Fig. 4 Hierarchical clustering of differentially expressed genes (DEGs). Hierarchical clustering during R. necatrix infection on avocado roots (RGA1, RGA2 and RGA3) in comparison with its in vitro growth on Potato Dextrose Agar media (RGPDA1, RGPDA2, RGPDA3). Red and green indicate upand down regulation, respectively

Table 1 qRT-PCR and RNA-Seq expression data of selected contigs over-expressed during R. necatrix growth on avocado roots

\begin{tabular}{llll}
\hline Gene ID & Description & RGA vs RGPDA \\
\cline { 2 - 4 } & & qRT-PCR FC & $\mathbf{8 3 8 . 6 8}$ \\
SAMD00023353_12800020 & Related to pisatin demethylase & $\mathbf{5 2 9 . 5 8}$ & $\mathbf{9 0 . 2 4}$ \\
SAMD00023353_2901300 & FAD-binding domain-containing protein & $\mathbf{1 6 0 . 7 8}$ & $\mathbf{7 7 . 0 4}$ \\
SAMD00023353_10000100 & Related to protoporphyrinogen oxidase & $\mathbf{1 2 9 . 6 4}$ & $\mathbf{1 0 4 . 0 4}$ \\
SAMD00023353_0800710 & Cytochrome p450 & $\mathbf{5 0 . 5 9}$ & $\mathbf{4 6 . 6 1}$ \\
\hline
\end{tabular}

${ }^{2}$ Data are displayed as fold change (FC), calculated by comparing R. necatrix growth on avocado roots (RGA) with $R$. necatrix growth on Potato Dextrose Agar medium (RGPDA). The expression data are the mean of three biological replicates. Bold numbers indicate statistically significant results $(t-T e s t, P<0.05)$ 


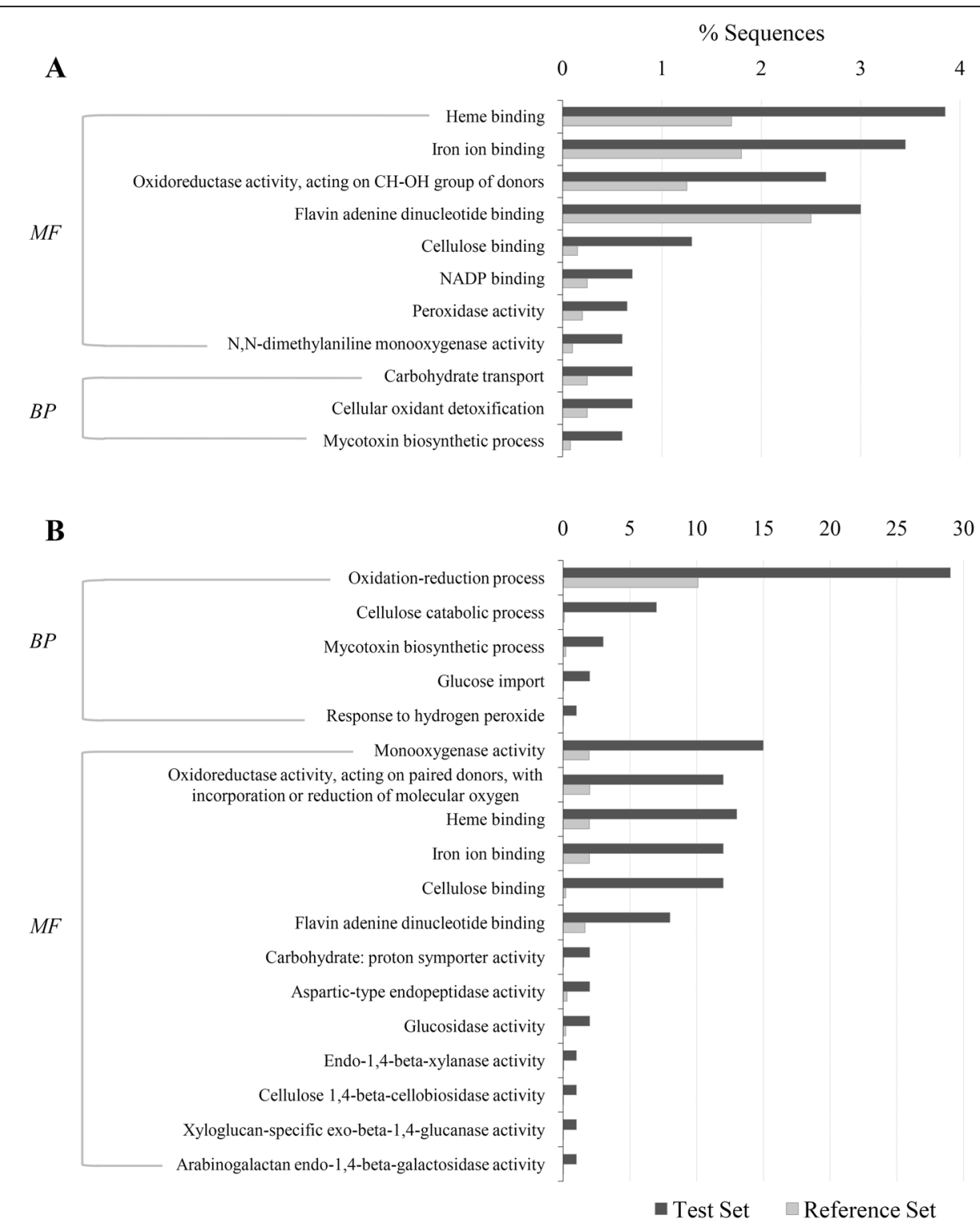

Fig. 5 Gene Ontology (GO) enrichment analysis of differentially expressed genes (DEGs). a. GO enrichment analysis of DEGs obtained in the transcriptome analysis of $R$. necatrix growing on avocado roots (RGA) in comparison with its growth on Potato Dextrose Agar media (RGPDA). $\mathbf{b}$. GO enrichment analysis of the TOP100 DEGs obtained in the transcriptome analysis of RGA vs RGPDA. Enrichment GO terms were obtained by Blast2GO using a cut-off of $P<0.05$. (BP) biological process; (MF) molecular function

0902760, SAMD00023353_12800020, SAMD00023353 3200110), and antibiotics (SAMD00023353_3600430, SAMD00023353 6600160, SAMD00023353_0702510, SAMD00023353_0100280, SAMD00023353_2201610), among other drugs. $R$. necatrix also over-expressed genes related to transport of toxic compounds, in particular, four (SAMD00023353_2601150, SAMD00023353_2501030, SAMD00023353_3000620 and SAMD00023353_6200040) and two contigs (SAMD00023353_10000080 and SAMD00023353_2200710) showed homology with genes encoding ATP-binding cassette $(\mathrm{ABC})$ transporters and major facilitator superfamily (MFS) transporters, respectively. Expression values of genes homologous to $\mathrm{ABC}$ transporters were higher (FC values ranging from 5 to 7 ) than those observed for MFS transporters (ranging from 2 to 3) (Table 4).

Two genes were selected for being associated with hormone biosynthesis $\left(\mathrm{GA}_{4}\right.$ desaturase family protein SAMD00023353_10100030 and gibberellin 20-oxidase SAMD00023353_1901120) showing FC values of 38.2 and 2.39 respectively and one gene, the argonaute siRNA chaperone complex subunit Arb1 (SAMD00023353. 0801000), postulated to play a role in RNA induced transcriptional silencing (Table 4). 
Table 2 The KEGG pathway analysis using differentially expressed genes (DEGs)

\begin{tabular}{ll}
\hline Category & Sequence number $^{\mathrm{a}}$ \\
\hline Nucleotides metabolism & 64 \\
Organic compounds metabolism & 60 \\
Metabolism of cofactors and vitamins & 58 \\
Amino acid metabolism & 48 \\
Carbohydrate metabolism & 42 \\
Antibiotics metabolism & 39 \\
Others & 37 \\
Drug metabolism & 28 \\
Lipid metabolism & 24 \\
Energy metabolism & 10 \\
Biosynthesis of other secondary metabolites & 8
\end{tabular}

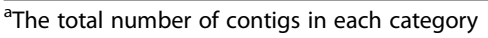

The RNAseq analysis also revealed 137 genes only expressed in $R$. necatrix during its growth on avocado roots. From those contigs, 24 were predicted as candidate effector proteins (CEP) by the CSIRO tool EffectorP2 (a machine learning method for fungal effector prediction in secretomes) [19] with a probability above $60 \%$ (Table 5). All CEPs, except for SAMD00023353_2100110, SAMD00023353_2801560, SAMD00023353_3900800, SAMD00023353_11900020 and SAMD00023353_1700590, showed no similarity with proteins in the public database. Out of the 24 CEP, 13 were predicted to be secreted by SignalP3 server and ten were determined to have an apoplastic localization by the CSIRO tool ApoplastP (a machine learning method for predicting localization of proteins) [20] (Table 5).

To test any existing relationship within the candidate effectors proteins identified in this study with previously described effectors proteins, the PHI (Pathogen Host Interaction) database was used; i.e., PHI-base is a database of virulence and effector genes that have been experimentally proven via pathogen-host interaction [21]. Blastp was used to match PHI-base with an e-value cutoff of 1E-03 and $30 \%$ identity. As result, $3 R$. necatrix candidate effectors were annotated, SAMD00023353_11900020 encoding a putative glycoside hydrolase, showed the higher percentage of identity with the effector Lysm from Penicillium expansum (Identity 44.58\%, E-value 9.94 E-53). SAMD00023353_2100110 and SAMD00023353_1700590 showed identity with effectors BEC1040 and Mocapn7 from Blumeria graminis (Identity $32.76 \%$, E-value $1.32 \mathrm{E}-05$ ) and Magnaporthe oryzae (Identity 35.82\%, E-value $1.32 \mathrm{E}-03$ ), respectively.

\section{Discussion}

Transcriptome analysis of $R$. necatrix strains growing on rich medium, has recently been addressed as an alternative to provide insights into plant pathogenicity mechanisms used by this ascomycete [12, 13]. However, neither of the two studies was carried out using $R$. necatrix directly interacting with a host. This current study fills this gap, obtaining and analyzing the transcriptomes of the virulent $\mathrm{CH} 53$ strain during infection of avocado roots and comparing it with that obtained from the fungus cultured in rich medium.

The number of predicted genes $(12,104)$ obtained in this study is congruent with data from previous transcriptomes from $R$. necatrix $(10,616$ [12];), as well as other plant pathogenic Ascomycota, such as Fusarium graminearum (13,332 genes [22];), Valsa mali (13,046 genes [11];), or Magnaporte oryzae (11,101 genes [23];). When comparing gene expression profiles between $R$. necatrix infecting avocado roots or growing on PDA medium, a number of transcripts were related with major fungal traits involved in the interaction with the host, among others, CWDE [24], production of toxic compounds and detoxification of those produced by the host, or potential effectors.

Phytopathogenic fungi usually produce numerous extracellular enzymes in order to penetrate the host tissue, being cell wall hydrolases and pectinases the most important ones [25]. The high number of CWDE overexpressed during the infection process correlates with previous visualization studies of $R$. necatrix hyphae that directly penetrate through the avocado root cells [9]. In addition, five putative proteases were also identified. Interestingly, gene expression studies carried out on avocado revealed that three protease inhibitors were highly over-expressed in tolerant rootstocks to $R$. necatrix following inoculation with the pathogen but not in susceptible genotypes [10]. This finding suggests that these proteases, up-regulated in $R$. necatrix during the infection process, could play an important role in degrading basal defense proteins on susceptible avocado roots, however, future experiments need to be carried out to confirm this hypothesis.

Several studies support the idea that $R$. necatrix produce toxins that are likely responsible for the symptoms observed in the aerial parts of the plant $[26,27]$. Cytochalasin $\mathrm{E}$ and rosnecatrone toxins produced by $R$. necatrix $[28,29]$ are believed to be involved in the onset of disease symptoms in young apple shoots and detached apple leaves [27]. Shimizu et al., [13], identified the cytochalasin biosynthetic gene cluster, containing fourteen genes, within a $36 \mathrm{~kb}$ region of the $R$. necatrix strain W97 genome. In the present study, only one gene (putative aflatoxin B1 aldehyde reductase protein) of the putative cytochalasin cluster was highly up-regulated, while it 
Table 3 R. necatrix genes encoding cell wall degrading enzymes

\begin{tabular}{|c|c|c|}
\hline Gene ID & Description & Fold Change \\
\hline \multicolumn{3}{|l|}{ Cell Wall Degrading Enzymes } \\
\hline SAMD00023353_0503130 & Putative Glycoside hydrolase family 61 protein & 511.82 \\
\hline SAMD00023353_6500680 & Glycoside hydrolase family 61 protein & 259.37 \\
\hline SAMD00023353_4001240 & Glycosyl hydrolase family 43 protein & 226.29 \\
\hline SAMD00023353_4000040 & Glycoside hydrolase family 128 protein & 201.63 \\
\hline SAMD00023353_5900080 & Putative glycoside hydrolase family 61 & 193.76 \\
\hline SAMD00023353_2700270 & Putative endoglucanase & 166.44 \\
\hline SAMD00023353_10700130 & Glycoside hydrolase family 128 protein & 162.43 \\
\hline SAMD00023353_3200340 & Glycoside hydrolase family 61 protein & 155.24 \\
\hline SAMD00023353_0105480 & Glycosyl hydrolase family 7 & 132.66 \\
\hline SAMD00023353_11500050 & Cellobiohydrolase II & 95.38 \\
\hline SAMD00023353_3900390 & Probable endoglucanase & 88.85 \\
\hline SAMD00023353_1201160 & Glycoside hydrolase family 3 protein & 71.42 \\
\hline SAMD00023353_4000610 & Glycoside hydrolase family 74 protein & 64.97 \\
\hline SAMD00023353_5100270 & Glycoside hydrolase family 5 protein & 56.75 \\
\hline SAMD00023353_3601090 & Putative glycoside hydrolase family 31 & 54.51 \\
\hline SAMD00023353_1700720 & Glycosyl hydrolase family 10 & 52.82 \\
\hline SAMD00023353_0202710 & Glycoside hydrolase family 53 protein & 42.82 \\
\hline SAMD00023353_3700510 & Glycoside hydrolase family 61 protein & 37.07 \\
\hline SAMD00023353_5100760 & Glycosylhydrolase family 61-5 & 36.69 \\
\hline SAMD00023353_0502040 & Glycoside hydrolase family 5 protein & 28.51 \\
\hline SAMD00023353_1901740 & Glycosyl hydrolase family 1 & 24.70 \\
\hline SAMD00023353_3000290 & Glycosyl hydrolase family 16 & 14.86 \\
\hline SAMD00023353_0204000 & Glycosyl hydrolase family 26 & 11.21 \\
\hline SAMD00023353_7600160 & Glycosyl hydrolase family 61 & 9.35 \\
\hline SAMD00023353_4000450 & Glycosyl hydrolase family 18 & 7.44 \\
\hline SAMD00023353_1601380 & Cutinase & 7.15 \\
\hline SAMD00023353_0400070 & Glycosyl hydrolase family 76 & 2.77 \\
\hline SAMD00023353_0201450 & Glycosyl hydrolase & 2.76 \\
\hline SAMD00023353_1002100 & Glycosyl hydrolase & 2.28 \\
\hline SAMD00023353_0101450 & Glycosyl hydrolase & 2.24 \\
\hline
\end{tabular}

${ }^{\mathrm{a}} \mathrm{RNA}$-Seq fold change calculated by comparing $R$. necatrix growth on roots vs Potato Dextrose Agar

was down-regulated in transcriptomic analyses carried out in the hypovirulent $R$. necatrix strain [13] (Additional file 2). Taking this into consideration, this gene could play an important role in the pathogenicity of $R$. necatrix $\mathrm{CH} 53$ on avocado roots, however the role of the cytochalasin $\mathrm{E}$ in virulence remains unclear as suggested by other authors [30]. Four more genes related with the production of fungal toxins were up-regulated during the infection process, two of them (putative sterigmatocystin 8-O-methyltransferase and the averantin oxidoreductase) had been previously described to be involved in aflatoxin biosynthesis [31]. Aflatoxins are considered as the most toxic and carcinogenic compounds among the known mycotoxins and 25 clustered genes have been reported to be involved in its biosynthesis [31, 32]. Although the expression of other genes potentially involved in aflatoxin biosynthesis was not observed and no aflatoxin production, even at minimum concentration $(<1 \mu \mathrm{g} / \mathrm{Kg})$, was detected in wheat grains infected with $R$ necatrix (data not shown), future studies should address the detection of this compound on infected roots due to its high toxigenic nature.

As other necrotrophic pathogens, $R$. necatrix seems to have adapted mechanisms to detoxify host metabolites that can interfere with its virulence [33]. Nineteen genes potentially involved in detoxification of antimicrobial compounds were significantly over-expressed. Interestingly, SAMD00023353_12800020 and SAMD00023353_ 
Table 4 Genes of $R$. necatrix potentially involved in pathogenesis

\begin{tabular}{|c|c|c|}
\hline Gene ID & Description & Fold Change ${ }^{a}$ \\
\hline \multicolumn{3}{|l|}{ Genes Related to Proteases } \\
\hline SAMD00023353_1500930 & Putative acid proteinase protein & 411.34 \\
\hline SAMD00023353_6300370 & Putative subtilisin-like protein & 13.44 \\
\hline SAMD00023353_3200760 & Putative subtilisin-like protein & 12.19 \\
\hline SAMD00023353_4000440 & Putative aspartyl protease & 4.82 \\
\hline SAMD00023353_0403740 & Related to subtilisin DY & 2.60 \\
\hline \multicolumn{3}{|c|}{ Genes Related to Toxins Production } \\
\hline SAMD00023353_5500610 & Putative aflatoxin B1 aldehyde reductase member 2 & 18.65 \\
\hline SAMD00023353_3901210 & Putative averantin oxidoreductase & 13.89 \\
\hline SAMD00023353_10000060 & Putative toxin biosynthesis & 4.81 \\
\hline SAMD00023353_1501590 & Putative toxin biosynthesis protein & 4.30 \\
\hline SAMD00023353_11700090 & Sterigmatocystin 8-O-methyltransferase & 3.29 \\
\hline \multicolumn{3}{|c|}{ Genes Related to Detoxification of Toxic Compounds } \\
\hline SAMD00023353_5200870 & catA, catalase & 157.78 \\
\hline SAMD00023353_3600430 & Putative cycloheximide resistance protein & 92.12 \\
\hline SAMD00023353_12800020 & Related to pisatin demethylase cytochrome P450 & 90.24 \\
\hline SAMD00023353_7000300 & GMC oxidoreductase & 41.39 \\
\hline SAMD00023353_8000300 & Beta-lactamase family protein & 40.99 \\
\hline SAMD00023353_1100640 & GMC oxidoreductase & 28.74 \\
\hline SAMD00023353_10400180 & Glucose-methanol-choline (GMC) oxidoreductase & 21.40 \\
\hline SAMD00023353_10400170 & Glucose-methanol-choline (GMC) oxidoreductase & 19.54 \\
\hline SAMD00023353_0701730 & Putative multidrug resistance protein fnx1 & 12.69 \\
\hline SAMD00023353_6600160 & Beta-lactamase family protein & 11.24 \\
\hline SAMD00023353_0702510 & Putative ciclohexymide resistance protein & 7.18 \\
\hline SAMD00023353_0902760 & Putative MFS aflatoxin efflux pump detoxificación & 3.87 \\
\hline SAMD00023353_4900180 & Putative arrestin domain containing protein & 3.40 \\
\hline SAMD00023353_2900030 & GMC oxidoreductase & 2.77 \\
\hline SAMD00023353_0100280 & Putative tetracycline resistance protein TCRI & 2.76 \\
\hline SAMD00023353_11800200 & Putative drug resistance protein & 2.68 \\
\hline SAMD00023353_3200110 & Putative pisatin demethylase & 2.39 \\
\hline SAMD00023353_3500410 & GMC oxidoreductase & 2.19 \\
\hline SAMD00023353_2201610 & Metallo-beta-lactamase superfamily protein & 2.07 \\
\hline \multicolumn{3}{|c|}{ Genes Related to Transport of Toxic Compounds } \\
\hline SAMD00023353_2601150 & $A B C$ transporter & 7.37 \\
\hline SAMD00023353_2501030 & $A B C$ transporter & 6.64 \\
\hline SAMD00023353_3000620 & $A B C-2$ type transporter & 5.38 \\
\hline SAMD00023353_10000080 & Putative MFS multidrug transporter protein & 3.28 \\
\hline SAMD00023353_2200710 & MFS transporter & 2.80 \\
\hline SAMD00023353_6200040 & ABC transporter cdr4 & 2.39 \\
\hline SAMD00023353_7300370 & Drug proton antiporter yhk8 & 2.21 \\
\hline \multicolumn{3}{|c|}{ Genes Related to Gibberelin Biosynthesis } \\
\hline SAMD00023353_10100030 & GA4 desaturase family protein & 38.02 \\
\hline SAMD00023353_1901120 & Gibberellin 20-oxidase & 2.39 \\
\hline \multicolumn{3}{|l|}{ Gene Related to Gene Silencing } \\
\hline SAMD00023353_0801000 & Argonaute siRNA chaperone complex subunit Arb1 & 2.38 \\
\hline
\end{tabular}

${ }^{a}$ RNA-Seq fold change calculated by comparing $R$. necatrix growth on roots vs Potato Dextrose Agar 
Table 5 List of candidate effectors genes in R. necatrix

\begin{tabular}{|c|c|c|c|c|c|}
\hline Gene ID & Description & CDS Length & Signal peptide & Effector prediction ${ }^{a}$ & Localization \\
\hline SAMD00023353_2100110 & SSCRP protein & 923 & Yes & 0.936 & Apoplastic \\
\hline SAMD00023353_1002580 & Hypothetical protein & 183 & No & 0.910 & Non-apoplastic \\
\hline SAMD00023353_3000810 & Hypothetical protein & 594 & Yes & 0.890 & Apoplastic \\
\hline SAMD00023353_1201650 & Hypothetical protein & 400 & Yes & 0.889 & Apoplastic \\
\hline SAMD00023353_4800590 & Hypothetical protein & 292 & No & 0.865 & Non-apoplastic \\
\hline SAMD00023353_1401580 & Hypothetical protein & 230 & Yes & 0.864 & Apoplastic \\
\hline SAMD00023353_5300760 & Hypothetical protein & 216 & No & 0.842 & Non-apoplastic \\
\hline SAMD00023353_2801560 & Putative lactoylglutathione lyase & 630 & No & 0.835 & Non-apoplastic \\
\hline SAMD00023353_7700300 & Hypothetical protein & 207 & Yes & 0.829 & Non-apoplastic \\
\hline SAMD00023353_1401720 & Hypothetical protein & 189 & No & 0.819 & Apoplastic \\
\hline SAMD00023353_9200230 & Hypothetical protein & 240 & Yes & 0.815 & Non-apoplastic \\
\hline SAMD00023353_6400250 & Hypothetical protein & 189 & Yes & 0.805 & Apoplastic \\
\hline SAMD00023353_0600790 & Hypothetical protein & 288 & No & 0.805 & Non-apoplastic \\
\hline SAMD00023353_2100970 & Hypothetical protein & 150 & No & 0.804 & Non-apoplastic \\
\hline SAMD00023353_3900800 & Cytochrome P450 monooxygenase & 360 & No & 0.802 & Non-apoplastic \\
\hline SAMD00023353_1901790 & Hypothetical protein & 501 & No & 0.784 & Non-apoplastic \\
\hline SAMD00023353_13300070 & Hypothetical protein & 273 & No & 0.765 & Non-apoplastic \\
\hline SAMD00023353_0104930 & Short-chain dehydrogenase reductase & 195 & No & 0.764 & Non-apoplastic \\
\hline SAMD00023353_0103460 & Hypothetical protein & 336 & Yes & 0.756 & Apoplastic \\
\hline SAMD00023353_11900020 & Glycoside hydrolase & 705 & Yes & 0.753 & Apoplastic \\
\hline SAMD00023353_1700590 & Ankyrin repeat domain-containing 52 & 246 & Yes & 0.731 & Non-apoplastic \\
\hline SAMD00023353_2400240 & Hypothetical protein & 585 & Yes & 0.721 & Apoplastic \\
\hline SAMD00023353_6500130 & Hypothetical protein & 1340 & Yes & 0.615 & Apoplastic \\
\hline SAMD00023353_1000090 & Hypothetical protein & 177 & Yes & 0.603 & Non-apoplastic \\
\hline
\end{tabular}

${ }^{a}$ Effectors prediction 'EffectorP 2' (http://effectorp.csiro.au/). Probability $>60 \%$

3200110, both repressed in the hypovirulent $R$. necatrix strain [13], showed homology to genes previously described to be involved in detoxification of phytoalexins. The importance of phytoalexin degradation ability in pathogenesis has been proved through transformation experiments [34]. To date, no phytoalexin production has been reported in 'Dusa' avocado rootstocks however, mutation experiments of these two genes would be of great interest to reveal their role in degradation of possible fungal toxic compounds produced by avocado roots.

Other contigs were related to transport mechanisms by which endogenous and exogenous toxicants can be secreted. Two major classes of transporter proteins were represented in $R$. necatrix DEGs such as ABC and MFS transporters. Members of both classes can have broad and overlapping substrate specificities for toxic compounds and have been considered as a "first-line fungus defense barrier" [35].

Some necrotrophs are also able to influence host phytohormone levels or employ their own hormone biosynthesis machinery thereby disrupting defense signaling
[24, 36-41]. Two genes involved in gibberellin biosynthesis, $\mathrm{GA}_{4}$ desaturase family protein and Gibberellin 20-oxidase, were up-regulated during the infection process. Role of GAs in plant-pathogen interactions is not well known [42]; i.e., Studt et al. [43] showed the positive relation between GA production and bakanae disease in rice while Manka [44] found no correlation between GA production and pathogenesis of Fusarium.

Throughout the infection process, fungi can actively manipulate host cellular machinery in order to suppress defenses and/or aid disease progression throughout the release of the so-called 'effector' proteins [45]. These effectors are usually secreted proteins that act at the host cell surface [46] or are taken up by the plant cell and act internally [47]. In this investigation, a total of 23 genes were predicted to be effectors (with probability above $60 \%$ ), among which 19 encoded for hypothetical proteins and 10 were predicted as apoplastic effectors, being their place of action the interphase between the hyphae and the host cell. One of the predicted effectors, showed homology to the Lysm1 effector of Penycilium expansum. Lysm-containing proteins have been proposed to 
be involved in binding and sequestering chitin oligosaccharides in order to prevent elicitation of host immune responses [48] and/or to protect fungal hyphae against chitinases secreted by competitors [49]. In this sense, the expression of this effector during $R$. necatrix infection correlates with previous studies in which the overexpression of chitinases on susceptible avocado rootstocks $/ R$. necatrix interaction, was reported [10]. Finally, other contig showed homology with the previously described Blumeria graminis effector gene BEC1040, which reduces haustoria formation in barley powdery mildew when silenced [50]. These results confirm previous observations by [12], in which BEC1040 homologous effectors in the virulent $R$. necatrix strain KACC40445 were found.

\section{Conclusion}

This study revealed, for the first time, several genes potentially associated with $R$. necatrix pathogenesis on avocado roots. The analysis of the full-length transcriptome of $R$. necatrix during the infection process suggests that the success of this fungus to infect diverse crops might be attributed to a number of produced compounds such as CWDE, toxins, antimicrobial detoxification compounds, transporters, effectors which, singly or in combination, likely interfere with defense or signaling mechanisms found on different plant families [24]. These results are revealing the complexity underlying $R$. necatrix pathogenesis being consistent with the difficulty of WRR management.

Functional characterization of these genes could help to understand how the fungus interferes with the host machinery and the development of white root rot disease. Along this line, a genetic manipulation protocol for transformation of $R$. necatrix has been established, although its efficiency needs to be improved [9]. Nevertheless, the transcriptome analysis of $R$. necatrix during the infection process provides useful information and facilitates further research to a more in -depth understanding of the biology and virulence of this pathogen. In turn, this will make possible to evolve novel strategies for white root rot management in avocado.

\section{Methods}

\section{Plant material, fungal isolate and inoculation}

Clonal 1 year old 'Dusa ${ }^{\mathrm{Tm} s}$ plants, described as susceptible to $R$. necatrix [51] and provided by Brokaw nursery (Brokaw España S.L), were potted in $1.5 \mathrm{~L}$ plastic pots, previously disinfected with hypochlorite solution (2\%) with an sterilized substrate consisting in peat, coconut fibre and perlite mixture (10:10:1) supplemented with $12 \mathrm{~g}$ osmocote $^{\circ}$ and placed into a semi-controlled greenhouse conditions $\left(\sim 20^{\circ} \mathrm{C}\right.$ temperature and $\sim 60 \%$ relative humidity). The virulent $\mathrm{CH} 53$ fungal strain, isolated at Almuñecar (Granada, Spain) [52], was used in this study and cultured on potato dextrose agar (PDA; Difco Laboratories, Detroit, USA) at $25^{\circ} \mathrm{C}$.

For transcriptome analysis of $R$. necatrix growing on rich medium, the isolate was cultured on PDA covered with a perforated layer of cellophane and incubated 5 days at $25^{\circ} \mathrm{C}$.

For RNA-Seq analysis of $R$. necatrix during infection, plants were removed from the pot and roots were washed with distilled water to remove soil debris. Roots were cut and placed into $15 \mathrm{~cm}$ diameter Petri dishes covered with three layers of filter paper soaked with sterilized distilled water. Three perforated cellophane discs, $6 \mathrm{~cm}$ diameter, were placed along the roots (Fig. 1). The inoculation was carried out by placing two wheat grains infected with $R$. necatrix onto each cellophane disc. Petri dishes were closed, sealed with parafilm and incubated in dark for 5 days.

\section{RNA isolation and sequencing}

For RNA extractions, cellophane discs covered with grown mycelium, were collected and macerated with liquid nitrogen using a mortar and pestle. One g of frozen powder was collected in a $2 \mathrm{ml}$ Eppendorf and resuspended in $1 \mathrm{ml}$ of denaturation solution (guanidine thiocyanate, $4 \mathrm{M}$, Na-citrate $25 \mathrm{mM}$ sarcosyl, 0.5\%) (Fluka; Switzerland) and saturated phenol $\mathrm{pH} 4.3$ (1:1) plus $7 \mu \mathrm{l}$ of $\beta$-Mercaptoethanol. One hundred $\mu$ l chloroform were added to the mixture; samples were vortexed and incubated $3 \mathrm{~min}$ at room temperature and centrifuged at 12 , $000 \mathrm{~g}$ for $10 \mathrm{~min}$ at $4{ }^{\circ} \mathrm{C}$. Afterwards, RNA was extracted using NucleoSpin RNA plant kit (Macherey-Nagel, Germany) following manufacturer's instructions.

DNAase I (DNase I, Thermo, USA) treatment was carried out twice, during and after the extraction process. RNA quantity and quality were determined based on absorbance ratios at $260 \mathrm{~nm} / 280 \mathrm{~nm}$ and $260 \mathrm{~nm} / 230 \mathrm{~nm}$ using a NanoDrop ${ }^{\circ}$ ND-1000 (Nanodrop Technologies, Inc., Montchanin, USA) spectrophotometer. RNA integrity was confirmed by the appearance of ribosomal RNA bands and lack of degradation products after separation on a $2 \%$ agarose gel and Red Safe staining.

The integrity of the RNA samples was further verified using the 2100 Bioanalyzer (Agilent Technologies, Inc., Santa Clara, USA) and submitted to the Centre Nacional d'Anàlisi Genòmica (CNAG, Barcelona, Spain) for sequencing. Two $\mu \mathrm{g}$ RNA from each sample were used for RNA library preparation using the TruSeq RNA Sample Preparation Kit (Illumina Inc) according to the protocols recommended by the manufacturer. Each library was paired-end sequenced $(2 \times 76 \mathrm{bp})$ by using the TruSeq SBS Kit v3-HS, in a HiSeq2000 platform. More than 40 million reads were generated for each sample. The RNA-Seq reads from six libraries (three biological 
replicates per condition) were processed to remove adaptor sequences, empty reads, low-quality sequences with a Phred score lower than 20 and short reads $(<25$ bp). Resulting reads were stored in FASTQ format. High quality reads were aligned to the $R$. necatrix reference genome [13] for generation of read counts and differential expression analysis. CH53 RNA-seq reads were mapped to the W97 genome and consensus sequences were made of the mapped reads. The overall rate of base changes in the mapped regions between the $\mathrm{CH} 53$ and W97 strains was $0.75 \%$. Raw reads from three biological replicates of $R$. necatrix growing on avocado roots and PDA media, are available from the NCBI Gene Expression Omnibus under accession number GSE134243.

A statistical analysis of the expression data of $R$. necatrix growing on avocado roots (RGA) vs Potato Dextrose Agar (RGPDA) media was performed by the Empirical analysis of DGE (EDGE) in CLC Genomics Workbench 10.0.0 (CLC Bio, Aarhus, Denmark). The DEGs were identified using the following conditions: $-2>$ fold change $>2$ and FDR $(P<0.05)$. A visual representation of DEGs $\log _{10}$ FDR $P$-value vs $\log _{2}$ Fold change was plotted in $\mathrm{R}$ (version 3.6) with a simple scatterplot color coding the different conditions.

\section{Gene predictions and annotations}

$R$. necatrix predicted genes were searched against NCBI Fungi databases to assign associated Gen Ontology (GO) annotations using Blast2Go [18]. GO enrichment analysis (Fisher's Exact test, [53]) and KEGG pathway analyses were carried out by Blast2go 5.2.4. Default parameters were used with a cut-off FDR of 0.05. GO enrichment analysis (Fisher's Exact test, [53]) describing the enriched biological processes (BP), molecular functions (MF) and cellular components (CC) of DEGs was performed with B2G according to the following parameters: filter mode as P-Value and 0.05 as filter value. Kyoto Encyclopedia of Genes and Genomes (KEGG) annotations [54] of DEGs was performed with B2G.

Genes were clustered using TIGR Multi Experiment Viewer 4.6.1 [55] with Euclidean distances and Average linkage.

SignalP 3.0 server [56] was used to predict the presence and location of signal peptide cleavage sites in amino acid sequences. Localization of proteins to the plant apoplast was predicted by the CSIRO tool ApoplastP [20]. Relationships within the candidate effectors proteins identified in this study with previously described effectors proteins was tested using the PHI (Pathogen Host Interaction) database [21].

\section{Quantitative real-time PCR}

Validation of gene expression levels obtained from the transcriptome analysis was performed using qRT-PCR.
One $\mu \mathrm{g}$ of total RNA was treated with DNase RNase-free (Promega, Madison, USA) following the manufacturer's instructions. Single-stranded cDNA was synthesized using the iScript cDNA synthesis kit (BIO-RAD, California, USA) following the manufacturer's instructions. The expression of five $R$. necatrix genes was studied. One endogenous control gene, actin, was used for normalization. Primer sequences for endogenous control gene and the five $R$. necatrix genes are presented in Additional file 3. Primer pairs were chosen to generate fragments between 50 and $150 \mathrm{bp}$ with melting temperature of $60^{\circ} \mathrm{C}$ and designed using Primer 3 software [57, 58].

Primer specificity was tested by first performing a conventional PCR and confirmed by the presence of a single melting curve during qRT-PCR. Serial dilutions $(1: 10,1: 20,1: 50,1: 200)$ were made from a pool of cDNA and calibration curves were performed for each gene. The qRT-PCR reaction mixture consisted of cDNA first-strand template, primers $(500 \mathrm{nmol}$ final concentration) and SYBR Green Master Mix (SsoAdvanced Universal SYBR Green Supermix, BioRad) in a total volume of $20 \mu$ l. The PCR conditions were as follows: $30 \mathrm{~s}$ at $95^{\circ} \mathrm{C}$, followed by 40 cycles of $10 \mathrm{~s}$ at $95^{\circ} \mathrm{C}$ and $15 \mathrm{~s}$ at $60^{\circ} \mathrm{C}$. The reactions were performed using an iQ5 real-time PCR detection system (Bio-Rad). Relative quantification of the expression levels for the target was performed using the comparative Ct method [59]. Three biological replicates of RGA or RGPDA vs control samples were performed in triplicate. Statistical significance of the data was determined by a Student's $t$-test carried out with Sigma Stat version 4.0 software (Systat Software GmbH).

\section{Supplementary information}

Supplementary information accompanies this paper at https://doi.org/10. 1186/s12864-019-6387-5.

Additional file 1. Top 20 overexpressed and repressed genes in $R$. necatrix during growth on avocado roots

Additional file 2. Genes within the region containing the putative cytochalasin biosynthetic gene cluster in $R$. necatrix

Additional file 3. QRT-PCR primer sequences used in this study

\section{Abbreviations}

BP: Biological process; CWDE: Cell wall degrading enzymes; DEG: Differentially expressed genes; FC: Fold change; GO: Gene ontology; KEGG: Kyoto encyclopedia of genes and genomes; MF: Molecular function; PDA: Potato dextrose agar; PHI: Pathogen host interactions; RGA: Rosellinia necatrix growing on avocado roots; RGPDA: Rosellinia necatrix growing on PDA; WRR: White Root Rot

Acknowledgements

Not applicable.

Authors' contributions

CP planed and designed the experiments and obtained the funding. AZ, HN, SK, AM, FPA and CP conducted the experiments, collected and analyzed the 
data. AZ, AB, EMF, CLH, FPA, FC and CP prepared the draft. All authors wrote, reviewed and edited the manuscript. All authors read and approved the final manuscript.

\section{Authors' information}

Not applicable

\section{Funding}

This research was supported by RTA2017-00040-00-00 (INIA-AEI), AVA201601.14 and AVA2019.008 (20\% Junta de Andalucía, 80\% FEDER) as well as AGL2017-83368-C2-1-R (Ministerio de Ciencia e Innovación) grants. C Pliego is currently supported by an INIA-CCAA contract, co-financed by INIA (20\%) and FEDER (80\%). The funding bodies played no role in the design of the study and collection, analysis, and interpretation of data and in writing the manuscript.

\section{Availability of data and materials}

The data from this study are available from the NCBI Gene Expression Omnibus under accession number GSE134243.

\section{Ethics approval and consent to participate}

Not applicable.

\section{Consent for publication}

Not applicable.

\section{Competing interests}

The authors declare that they have no competing interests.

\section{Author details}

${ }^{1}$ Department of Genomics and Biotechnology, IFAPA, Fruticultura Subtropical y Mediterránea, Unidad Asociada de I + D + i al CSIC, Cortijo de la Cruz s/n, 29140 Málaga, Spain. ²Division of Apple Research, Institute of Fruit Tree and Tea Science, National Agriculture and Food Research Organization (NARO), 92-24 Nabeyashiki, Shimokuriyagawa, Morioka, Iwate 020-0123, Japan. ${ }^{3}$ Present Address: NIFTS, NARO, 2-1 Fujimoto, Tsukuba 360-8605, Japan. ${ }^{4}$ Department of Botany and Plant Physiology, Instituto de Hortofruticultura Subtropical y Mediterránea "La Mayora" (IHSM-UMA-CSIC), Unidad Asociada IHSM-IFAPA, University of Málaga, 29071 Málaga, Spain. ${ }^{5}$ Department of Crop Ecophysiology, IFAPA, Fruticultura Subtropical y Mediterránea, Unidad Asociada de I + D + i al CSIC, Cortijo de la Cruz s/n, 29140 Málaga, Spain. ${ }^{6}$ Instituto de Agricultura Sostenible, CSIC, Apdo. 4084, 144080 Córdoba, Spain. ${ }^{7}$ Department of Microbiology, Instituto de Hortofruticultura Subtropical y Mediterránea "La Mayora" (IHSM-UMA-CSIC), University of Málaga, 29071 Málaga, Spain.

Received: 26 July 2019 Accepted: 12 December 2019

Published online: 26 December 2019

\section{References}

1. Kulshrestha S, Seth CA, Sharma M, Sharma A, Mahajan R, Chauhan A. Biology and control of Rosellinia necatrix causing white root rot disease: a review. J Pure Appl Microbiol. 2014;8(3):1803-14.

2. Farr DF, Rossman AY. National Fungus Collections from United States Department of Agriculture. Agricultural Res Serv. http://nt.ars-grin.gov/ fungaldatabases/index.cfm. Accessed 30 May 2019.

3. Arakawa M, Nakamura $\mathrm{H}$, Uetake $\mathrm{Y}$, Matsumoto N. Presence and distribution of double-stranded RNA elements in the white root rot fungus Rosellinia necatrix. Mycoscience. 2002. https://doi.org/10.1007/s102670200004.

4. ten Hoopen GM, Krauss U. Biology and control of Rosellinia bunodes, Rosellinia necatrix and Rosellinia pepo: a review. Crop Prot. 2006. https://doi. org/10.1016/j.cropro.2005.03.009.

5. Petrini LE. Rosellinia species of the temperate zone. Sydowia. 1993;44: 169-281.

6. Sztejnberg A, Madar Z. Host range of Dematophora necatrix, the cause of white root rot disease in fruit trees. Plant Dis. 1980. https://doi.org/10.1094/ PD-64-662.

7. Pliego C, López-Herrera C, Ramos C, Cazorla FM. Developing tools to unravel the biological secrets of Rosellinia necatrix, an emergent threat to woody crops. Mol Plant Pathol. 2012. https://doi.org/10.1111/j.1364-3703. 2011.00753.x.
8. Arjona-Girona I, López-Herrera CJ. First report of Rosellinia necatrix causing white root rot in mango trees in Spain. Plant Dis. 2018. https://doi.org/10.1 094/PDIS-01-18-0133-PDN.

9. Pliego C, Kanematsu S, Ruano-Rosa D, de Vicente A, López-Herrera C, Cazorla FM, Ramos C. GFP sheds light on the infection process of avocado roots by Rosellinia necatrix. Fungal Genet Biol. 2009. https://doi.org/10.1016/ j.fgb.2008.11.009.

10. Zumaquero A, Martínez-Ferri E, Matas AJ, Reeksting B, Olivier NA, PliegoAlfaro $F$, et al. Rosellinia necatrix infection induces differential gene expression between tolerant and susceptible avocado rootstocks. PLoS One. 2019. https://doi.org/10.1371/journal.pone.0212359.

11. Ke X, Yin Z, Song N, Dai Q, Voegele RT, Liu Y, et al. Transcriptome profiling to identify genes involved in pathogenicity of Valsa mali on apple tree. Fungal Genet Biol. 2014. https://doi.org/10.1016/j.fgb.2014.04.004.

12. Kim H, Lee SJ, Jo IH, Lee J, Bae W, Kim H, et al. Characterization of the Rosellinia necatrix transcriptome and genes related to pathogenesis by single-molecule mRNA sequencing. Plant Pathol J. 2017. https://doi.org/10. 5423/PPJ.OA.03.2017.0046.

13. Shimizu T, Kanematsu S, Yaegashi H. Draft genome sequence and transcriptional analysis of Rosellinia necatrix infected with a virulent mycovirus. Phytopathology. 2018. https://doi.org/10.1094/PHYTO-11-170365-R.

14. Both M, Csukai M, Stumpf MPH, Spanu PD. Gene expression profiles of Blumeria graminis indicate dynamic changes to primary metabolism during development of an obligate biotrophic pathogen. Plant Cell. 2005. https:// doi.org/10.1105/tpc.105.032631.

15. Both M, Eckert SE, Csukai M, Muller E, Dimopoulos G, Spanu PD. Transcript profiles of Blumeria graminis development during infection reveal a cluster of genes that are potential virulence determinants. Mol Plant Microbe In. 2005. https://doi.org/10.1094/MPMl-18-0125.

16. Wei Y, Liu T, Zhu M, Zhang W, Li H, Huang Z, et al. De novo transcriptome analysis of plant pathogenic fungus Myrothecium roridum and identification of genes associated with trichothecene mycotoxin biosynthesis. Int J Mol Sci. 2017. https://doi.org/10.3390/ijms18030497.

17. Pérez-Nadales E, Almeida-Nogueira MF, Baldin C, Castanheira S, El

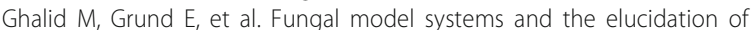
pathogenicity determinants. Fungal Genet Biol. 2014. https://doi.org/10. 1016/j.fgb.2014.06.011.

18. Conesa A, Gotz S, García-Gómez JM, Terol J, Talón M, Robles M. Blast2GO: a universal tool for annotation, visualization and analysis in functional genomics research. Bioinformatics. 2005. https://doi.org/10.1093/ bioinformatics/bti610.

19. Sperschneider J, Dodds PN, Gardiner DM, Singh KB, Taylor JM. Improved prediction of fungal effector proteins from secretomes with Effector P 2.0. Mol Plant Pathol. 2018. https://doi.org/10.1111/mpp.12682.

20. Sperschneider J, Dodds PN, Singh KB, Taylor JM. ApoplastP: prediction of effectors and plant proteins in the apoplast using machine learning. New Phytol. 2017. https://doi.org/10.1111/nph.14946.

21. Urban M, Cuzick A, Rutherford K, Irvine AG, Pedro H, Pant R, et al. PHI-base: a new interface and further additions for the multi-species pathogen-host interactions database. Nucleic Acids Res. 2017. https://doi.org/10.1093/nar/ gkw1089.

22. Cuomo CA, Güldener U, Xu JR, Trail F, Turgeon BG, di Pietro A, et al. The Fusarium graminearum genome reveals a link between localized polymorphism and pathogen specialization. Science. 2007. https://doi.org/ 10.1126/science. 1143708 .

23. Dean RA, Talbot NJ, Ebbole DJ, Farman ML, Mitchell TK, Orbach MJ, et al. The genome sequence of the rice blast fungus Magnaporthe grisea. Nature. 2005. https://doi.org/10.1038/nature03449.

24. Laluk K, Mengiste T. Necrotroph attacks on plants: wanton destruction or covert extortion? Arabidopsis Book. 2010. https://doi.org/10.1199/tab.0136.

25. Oliver RP, SVS I. Arabidopsis pathology breathes new life into the necrotrophs-vs.-biotrophs classification of fungal pathogens. Mol Plant Pathol. 2004. https://doi.org/10.1111/j.1364-3703.2004.00228.x.

26. Arjona-Girona I, Ariza M, López-Herrera C. Contribution of Rosellinia necatrix toxins to avocado white root rot. Eur J Plant Pathol. 2017. https://doi.org/10. 1007/s10658-016-1074-8.

27. Whalley AJS. The xylariaceous way of life. Mycol Res. 1996. https://doi.org/ 10.1016/S0953-7562(96)80042-6.

28. Edwards RL, Maitland DJ, Whalley AJ. Metabolites of the higher fungi. Part 24. Cytochalasin N, O, P, Q, and R. New cytochalasins from the fungus 
Hypoxylon terricola Mill. J Chem Soc Perkin Trans. 1989. https://doi.org/10. 1039/p19890000057.

29. Edwards RL, Maitland DJ, Whalley AJ. Metabolites of the higher fungi. Part 32. A phytotoxic bicyclo[4.1.0]hept-3-en-2-one from the fungus Rosellinia necatrix Prill. J Chem Soc Perkin Trans. 2001. https://doi.org/10.1039/ b008195q.

30. Kanematsu S, Hayashi T, Kudo A. Isolation of Rosellinia necatrix mutants with impaired cytochalasin E production and its pathogenicity. Ann Phytopath Soc Japan. 1997. https://doi.org/10.3186/jjphytopath.63.425.

31. Yu J, Chang PK, Ehrlich KC, Cary JW, Bhatnagar D, Cleveland TE, et al. Clustered pathway genes in aflatoxin biosynthesis. Appl Environ Microbiol. 2004. https://doi.org/10.1128/AEM.70.3.1253-1262.2004.

32. Yu J, Chang JW, Cary M, Wright D, Bhatnagar TE, Cleveland GA, et al. Comparative mapping of aflatoxin pathway gene clusters in Aspergillus parasiticus and Aspergillus flavus. Appl Environ Microbiol. 1995;61:2365-71.

33. Morrissey JP, Osbourn AE. Fungal resistance to plant antibiotics as a mechanism of pathogenesis. Microbiol Mol Biol Rev. 1999;63(3):708-24.

34. George H, VanEtten HD. Characterization of pisatin-inducible cytochrome P450s in fungal pathogens of pea that detoxify the pea phytoalexin pisatin. Fungal Genet Biol. 2001. https://doi.org/10.1006/fgbi.2001.1270.

35. del Sorbo G, Schoonbeek $H$, de Waard MA. Fungal transporters involved in efflux of natural toxic compounds and fungicides. Fungal Genet Biol. 2000. https://doi.org/10.1006/fgbi.2000.1206.

36. Bhattacharya A, Kourmpetli S, Ward DA, Thomas SG, Gong F, Powers SJ, et al. Characterization of the fungal gibberellin desaturase as a 2oxoglutarate-dependent dioxygenase and its utilization for enhancing plant growth. Plant Physiol. 2012. https://doi.org/10.1104/pp.112.201756.

37. Hou X, Lee LYC, Xia K, Yan Y, Yu H. DELLAs modulate jasmonate signaling via competitive binding to JAZs. Dev Cell. 2010. https://doi.org/10.1016/j. devcel.2010.10.024

38. Navarro L, Bari R, Achard P, Lison P, Nemri A, Harberd NP, et al. DELLAs control plant immune responses by modulating the balance and salicylic acid signaling. Curr Biol. 2008. https://doi.org/10.1016/j.cub.2008.03.060.

39. Patkar RN, Naqvi NI. Fungal manipulation of hormone-regulated plant defense. PLoS Pathog. 2017. https://doi.org/10.1371/journal.ppat.1006334.

40. Salazar-Cerezo S, Martínez-Montiel N, García-Sánchez J, Pérez-y-Terrón R, Martínez-Contreras RD. Gibberellin biosynthesis and metabolism: a convergent route for plants, fungi and bacteria. Microbiol Res. 2018. https:// doi.org/10.1016/j.micres.2018.01.010

41. Sharon A, Elad Y, Barakat R, Tudzynski P. Phytohormones in Botrytis-plant interactions. In: Elad Y, Williamson B, Tudznski P, Delen N, editors. Botrytis: biology, pathology and control. 1, vol. 8. Dordecht: Kluwer Academic Publishers; 2004. p. 163-79

42. Chanclud E, Morel JB. Plant hormones: a fungal point of view. Mol Plant Pathol. 2016. https://doi.org/10.1111/mpp,12393.

43. Studt L, Schmidt FJ, Jahn L, Sieber CMK, Connolly LR, Niehaus EM, et al. Two histone deacetylases, FfHda1 and FfHda2, are important for Fusarium fujikuroi secondary metabolism and virulence. Appl Environ Microbiol. 2013. https://doi.org/10.1128/AEM.01557-13

44. Manka M. Auxin and gibberellin-like substances synthesis by Fusarium isolates. Acta Microbiol Pol. 1980;29(4):365-74.

45. Dodds PN, Rathjen JP. Plant immunity: towards an integrated view of plantpathogen interactions. Nat Rev Genet. 2010. https://doi.org/10.1038/ nrg2812.

46. Stergiopoulos I, de Wit PJGM. Fungal effector proteins. Annu Rev Phytopathol. 2009. https://doi.org/10.1146/annurev.phyto.112408.132637.

47. Ellis JG, Dodds PN. Showdown at the RXLR motif: serious differences of opinion in how effector proteins from filamentous eukaryotic pathogens enter plant cells. Proc Natl Acad Sci U S A. 2011. https://doi.org/10.1073/ pnas. 1111668108.

48. Kombrink A, Thomma BPHJ. LysM effectors: secreted proteins supporting fungal life. PLoS Pathog. 2013. https://doi.org/10.1371/journal.ppat.1003769.

49. de Jonge $R$, Thomma BPHJ. Fungal LysM effectors: extinguishers of host immunity? Trends Microbiol. 2009. https://doi.org/10.1016/j.tim.2009.01.002.

50. Pliego C, Nowara D, Bonciani G, Gheroghe DM, Xu R, Surana P, et al. Hostinduced gene silencing in barley powdery mildew reveals a class of ribonuclease-like effertors. Mol Plant Microbe In. 2013. https://doi.org/10. 1094/MPMI-01-13-0005-R

51. Pérez-Jiménez RM. A review of the biology and pathogenicity of Rosellinia necatrix- the cause of white root rot disease of fruit trees and other plants. J Phytopathol. 2006. https://doi.org/10.1111/j.1439-0434.2006.01101.x.
52. López-Herrera CJ, Zea-Bonilla T. Effects of benomyl, carbendazim, fluazinam and thiophanate methyl on white root rot of avocado. Crop Prot. 2007. https://doi.org/10.1016/j.cropro.2006.10.015.

53. Bluthgen N, Brand K, Cajavec B, Swat M, Herzel H, Beule D. Biological profiling of gene groups utilizing gene ontology. Genome Inform. 2005. https://doi.org/10.11234/gi1990.16.106.

54. Kanehisa M, Goto S. KEGG: Kyoto encyclopedia of genes and genomes. Nucleic Acids Res. 2000. https://doi.org/10.1093/nar/28.1.27.

55. Saeed Al, Sharov V, White J, Li J, Liang W, Bhagabati N, et al. TM4: a free, open-source system for microarray data management and analysis. Biotechniques. 2003. https://doi.org/10.2144/03342mt01.

56. Bendtsen JD, Nielsen $H$, von Heijne $G$, Brunak S. Improved prediction of signal pertides: SignalP3.0. J Mol Biol. 2004. https://doi.org/10.1016/j.jmb. 2004.05.028

57. Koressaar T, Remm M. Enhancements and modifications of primer design program Primer3. Bioinformatics. 2007. https://doi.org/10.1093/ bioinformatics/btm091.

58. Untergasser A, Cutcutache I, Koressaar T, Ye J, Faircloth BC, Remm M, et al. Primer3- new capabilities and interfaces. Nucleic Acids Res. 2012. https://doi. org/10.1093/nar/qks596.

59. Pfaffl MW. A new mathematical model for relative quantification in real-time RT-PCR. Nucleic Acids Res. 2001. https://doi.org/10.1093/nar/29.9.e45.

\section{Publisher's Note}

Springer Nature remains neutral with regard to jurisdictional claims in published maps and institutional affiliations.
Ready to submit your research? Choose BMC and benefit from:

- fast, convenient online submission

- thorough peer review by experienced researchers in your field

- rapid publication on acceptance

- support for research data, including large and complex data types

- gold Open Access which fosters wider collaboration and increased citations

- maximum visibility for your research: over $100 \mathrm{M}$ website views per year

At BMC, research is always in progress.

Learn more biomedcentral.com/submissions 